Research Article

\title{
The Size Effect and Microstructure Changes of Granite after Heat Treatment
}

\author{
Zhongping Guo $\mathbb{D}^{1},{ }^{1}$ Jian Li $\left(\mathbb{D},{ }^{1,2}\right.$ Yongqi Song, ${ }^{1}$ Chengqian He, ${ }^{1}$ and Fuyu Zhang ${ }^{1}$ \\ ${ }^{1}$ College of Energy and Mining Engineering, Shandong University of Science and Technology, Qingdao 266590, China \\ ${ }^{2}$ College of Mining and Civil Engineering, Liupanshui Normal University, Liupanshui 553004, China
}

Correspondence should be addressed to Jian Li; skdlijian2017@sdust.edu.cn

Received 10 March 2021; Revised 17 June 2021; Accepted 22 June 2021; Published 2 July 2021

Academic Editor: Gianfranco Carotenuto

Copyright (c) 2021 Zhongping Guo et al. This is an open access article distributed under the Creative Commons Attribution License, which permits unrestricted use, distribution, and reproduction in any medium, provided the original work is properly cited.

\begin{abstract}
High temperature can change the mechanical properties of granite, with significant nonlinear characteristics, and at the same time change its microstructure. Therefore, two kinds of granites are used in this paper: one is normal temperature granite and the other is granite treated at $600^{\circ} \mathrm{C}$, and a detailed comparative study is made. The fracture toughness of two kinds of rocks was tested by fracture tests, and the results were analyzed by a nonlinear fracture mechanics model (SEL). At the same time, in order to understand the influence of high temperature on the mineral composition and microstructure of granite, XRD, optical microscope, and SEM were used to observe the mineral composition, microcracks, and fracture morphology of granite. The results show the following: (1) high temperature significantly changes the fracture mechanics parameters of granite. The fracture toughness of granite treated at $600^{\circ} \mathrm{C}$ is significantly lower than that of untreated granite, which is reduced by more than $60 \%$. (2) No obvious size effect was found in the untreated granite, while the size effect of the granite after treatment at $600^{\circ} \mathrm{C}$ was significant. (3) The granite after high-temperature treatment showed strong nonlinear characteristics, and the SEL can reasonably describe and explain its nonlinear fracture characteristics. (4) The brittleness of the granite treated at $600^{\circ} \mathrm{C}$ decreased and the ductility increased. The microscopic morphology of the fracture was rough, with obvious steps and rivers. The microcracks and porosity had increased significantly, but the main components did not change significantly.
\end{abstract}

\section{Introduction}

Due to the needs of nuclear waste storage, geothermal resource development, and many other engineering constructions [1-8], the mechanical properties of rocks after high temperature have caused extensive research by scholars.

So far, there are many reports on the fracture toughness of rocks after high temperature, including granite, marble, basalt, and other rocks [9]. In 2007, Nasseri et al. [10] tested the fracture toughness of Westerly granite after high temperature and found that the fracture toughness of granite continued to decrease with the increase of temperature, and the fracture toughness of granite treated at $800{ }^{\circ} \mathrm{C}$ decreased by more than $90 \%$.
In 2018, Talukdar et al. [11] heated three types of crystalline rocks in India and tested their fracture toughness. The results show that when the treatment temperature reaches $600^{\circ} \mathrm{C}$, the fracture toughness values of the three types of rocks are greatly reduced, exceeding $50 \%$. A large number of similar test results have similar findings; that is, the fracture toughness of the rock is significantly reduced $[2,12-17]$, as shown in Figure 1.

It should be noted that most of the above test reports are the apparent fracture toughness of the rock, rather than its true value. This is due to the influence of the fracture process zone (FPZ) [18]. As Funatsu et al. [19] pointed out, the FPZ of the rock is related to the shape of the sample and the loading conditions, and the impact of FPZ should be fully considered when testing. 


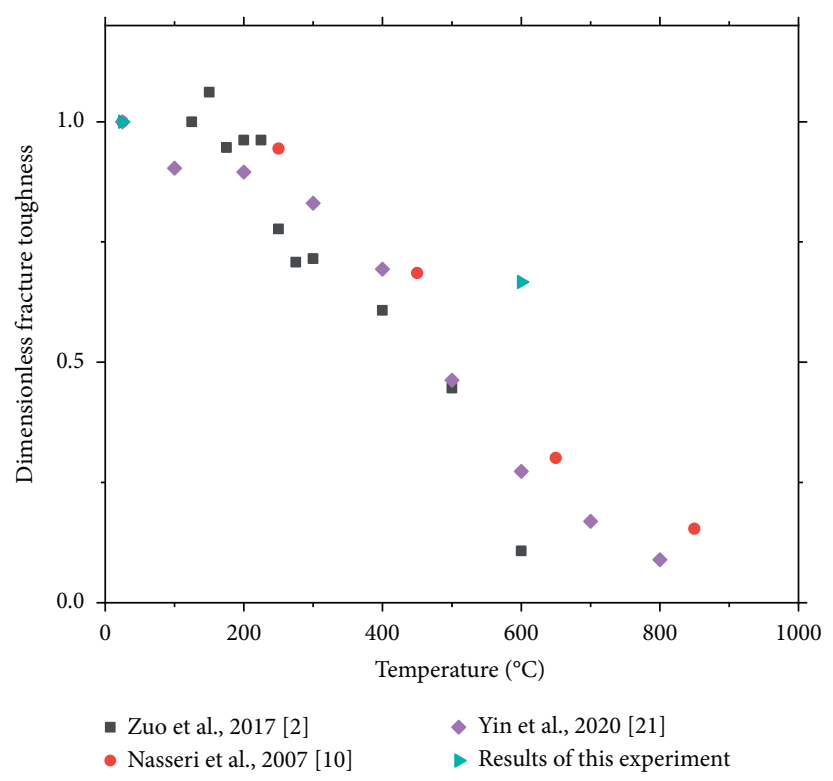

Figure 1: Relationship between fracture toughness and temperature.

The influence of FPZ on fracture toughness of thermally damaged rock should be considered. Miao et al. [20] carried out a fracture test of granite from room temperature to $800^{\circ} \mathrm{C}$ and used DIC technology to observe the strain on the rock surface. The results showed that a significant FPZ appeared at the crack tip of the rock specimen after hightemperature treatment; and as the processing temperature increases, the size of the FPZ becomes larger and larger. Yin et al. [21] and Zuo et al. [22] also conducted similar experiments and reported the parameters of the double-k model for heat-damaged rocks [23]. However, the application of nonlinear fracture mechanics in the study of rocks after heat treatment is not sufficient, especially regarding the size effect [24]. Generally, the size of the specimen used in the laboratory is usually smaller than the actual structural size. Due to the size effect, the mechanical properties measured in the laboratory are directly used to estimate the actual structural strength, which is inaccurate. This may lead to serious deviations, especially in the case of using smallsized samples and a large FPZ. The size effect law is the key to reasonably applying the laboratory results to the actual structure $[25,26]$.

Therefore, in this paper, two temperature levels and three different sizes of granite specimens are used for fracture tests. The size effect of heat-damaged granite has been paid more attention. At the same time, the characteristics of mineral composition and microcrack of heat-damaged granite were observed.

\section{Specimen Preparation and Investigation Methods}

2.1. Specimen Preparation. A medium-fine-grained granite produced in Zhangqiu, China, was used for this test [24, 27-29]. The diameters of the three types of semicircular bend (SCB) specimens were $50 \mathrm{~mm}, 100 \mathrm{~mm}$, and $200 \mathrm{~mm}$, the thickness was $40 \mathrm{~mm}$, and the initial crack length to radius ratio was 0.3 . At the same time, 6 standard Brazilian split disc samples were produced [30-32]. The detailed geometry and dimensions of the test piece are shown in Figure 2 and Table 1.

The specimens in this test are divided into two groups equally: one group (high temperature group) is processed at $600^{\circ} \mathrm{C}$ and the other group (room temperature group) is not processed. Use the intelligent muffle furnace to slowly heat the granite specimens of the high-temperature group at a heating rate of $5^{\circ} \mathrm{C} / \mathrm{min}$. When it reaches $600^{\circ} \mathrm{C}$, maintain the specimens at this temperature for $1 \mathrm{~h} \mathrm{[33]} \mathrm{and} \mathrm{then} \mathrm{stop}$ heating and let the specimens cool slowly $[10,34]$.

2.2. External Characteristics and Mineral Composition. High temperature usually changes the color of rocks; thus, the surfaces of the granite specimens were first observed, and the surface change phenomenon was observed in detail using an industrial microscope (Shenzhen Jingtuo Youcheng Technology Co. Ltd, JT-H6). Standard X-ray powder diffraction analysis (XRD, PANalytical X'Pert PRO) is used to determine the mineral composition of granite [14]. XRD patterns were recorded in the range $2-50^{\circ} 2 \theta$ with a speed of $6^{\circ} / \mathrm{min}$, operating voltage of $40 \mathrm{kV}$, and current of $40 \mathrm{~mA}$.

\subsection{Rock Mechanical Properties Test}

2.3.1. Fracture Toughness Testing. The three-point bending test was carried out on this batch of Zhangqiu granite specimens using the hydraulic servo-controlled testing machine model MTS 381.10. According to ISRM's recommendations $[28,35]$, the SCB specimens were loaded in displacement control mode $(0.05 \mathrm{~mm} / \mathrm{min})$, as shown in Figure 3(a). In order to avoid confusion, the fracture toughness value obtained by directly applying linear fracture mechanics is called the apparent fracture toughness $K_{\mathrm{if}}$. 


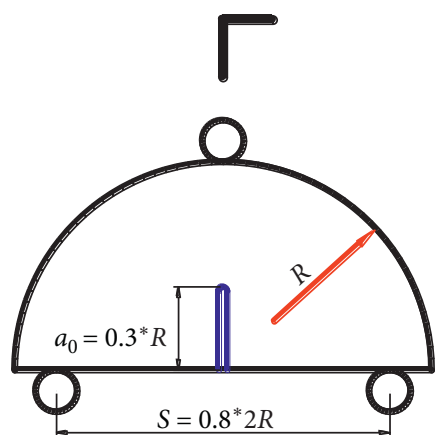

L

(a)

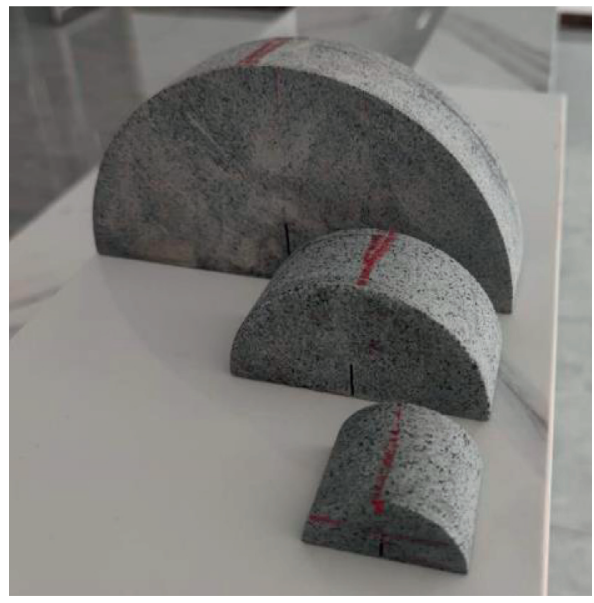

(c)

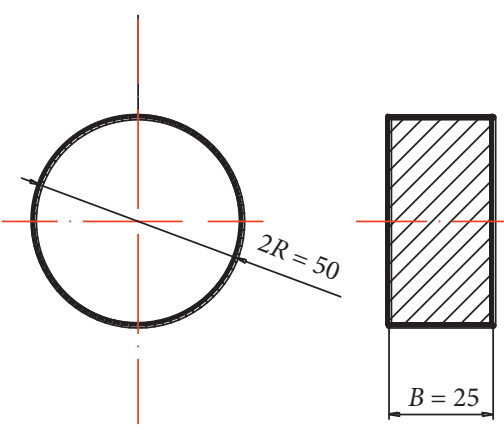

Unit: $\mathrm{mm}$

(b)

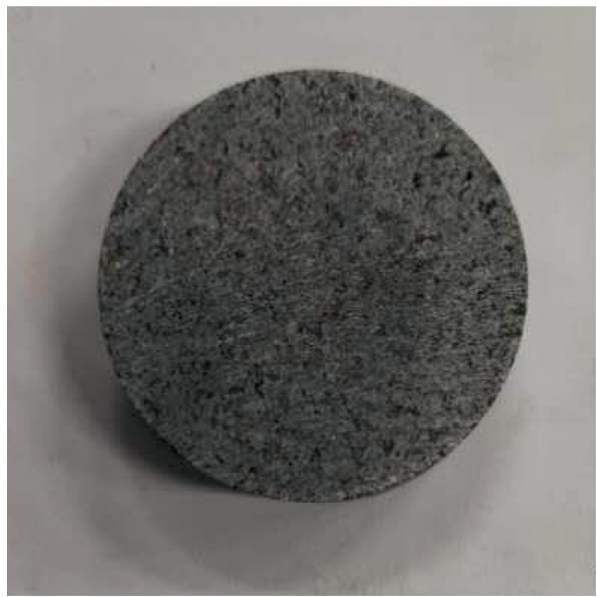

(d)

Figure 2: SCB specimens and BD specimens.

TABLE 1: Detailed geometric dimensions of the specimen.

\begin{tabular}{lccccc}
\hline Specimen type & Diameter $(\mathrm{mm})$ & Thickness $(\mathrm{mm})$ & Crack length, $a_{0}(\mathrm{~mm})$ & Crack length ratio $\left(a_{0} / R\right)$ & Number of specimens \\
\hline SCB-S & 50 & 40 & 7.5 & 0.3 & 6 \\
SCB-M & 100 & 40 & 15 & 0.3 & 6 \\
SCB-L & 200 & 40 & 30 & 0.3 & 6 \\
BD & 50 & 25 & - & - & 6 \\
\hline
\end{tabular}

According to the method recommended by ISRM [28], the specific formula is as follows.

The apparent fracture toughness $K_{\text {if }}$ is

$$
\left\{\begin{array}{l}
K_{i f}=Y \frac{P_{\max } \sqrt{\pi a_{0}}}{2 R B}, \\
Y=-1.297+9.516 \frac{S}{2 R}-\left(0.47+16.457 \frac{S}{2 R}\right) \beta \\
+\left(1.071+34.401 \frac{S}{2 R}\right) \beta^{2}, \\
\beta=\frac{a_{0}}{R},
\end{array}\right.
$$

where $P_{\max }$ is the peak load; $a_{0}$ is the initial crack length; $Y$ is the dimensionless stress intensity factor; $S$ is the pivot point spacing; $R$ is the radius; and $B$ is the thickness.

All SCB specimens are tested using the same span to diameter ratio $(2 R)$ of $S / 2 R=0.8$.

2.3.2. Tensile Strength. Brazilian disc splitting tests were performed on two types of granite (RT and 600) to obtain their tensile strength [30] (Figure 3(b)).

$$
\sigma_{t}=\frac{2 P_{\max }}{\pi D B}
$$

where $\sigma_{t}$ is the tensile strength; $P_{\max }$ is the peak load; $D$ is the diameter; and $B$ is the thickness. 


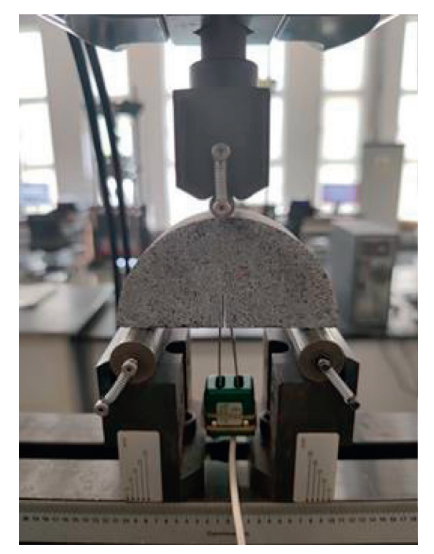

(a)

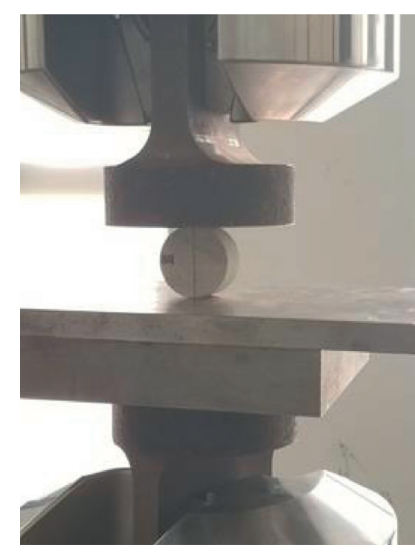

(b)

Figure 3: Fracture test and tensile strength test.

The same hydraulic servo-controlled MTS (MTS 381.10) testing machine as the three-point bending test was used to perform the Brazilian splitting test. The maximum load of specimen fracture was recorded by displacement controlled loading mode.

2.4. Optical Microscope. The two types of granite samples after the test were made into thin slices to observe the changes in the mineral composition and internal structure of the granite; and these thin slices were observed under a petrographic microscope (Zeiss Axioskop 40). Because ordinary thin slices are not easy to identify microcracks and other structures, in order to find these structures clearly and intuitively, the granite samples were impregnated with epoxy resin in a vacuum box; and these epoxy resins are added with blue dye to make them more eye-catching. In this way, the pore and crack structure could be analyzed very clearly and intuitively, and the porosity and other characteristics of the rock could be evaluated [36, 37].

2.5. SEM. The SEM analyses were performed on the sections of granite samples using the field emission gun scanning electron microscope (Hitachi SU8010), equipped with the energy-dispersive spectroscopy (HORABA Ltd,

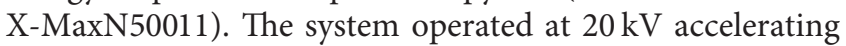
voltage in a high-vacuum mode. The sections of granite samples were coated with gold [38]. The microstructure of granite fracture can be observed directly and conveniently by SEM [39]. EDS is used to observe changes in the composition of minerals in rocks.

\section{Experimental Results}

3.1. External Characteristics. The color of granite samples after heat treatment is the most intuitive indicator of the impact of the treatment. Comparing the specimens, it was found that the specimen surface color changed from dark to light after $600^{\circ} \mathrm{C}$, with brownish-red spots, as shown in Figures 4(a) and 4(b). This phenomenon could be observed more clearly after magnified observation through an industrial microscope (Figures 4(c) and 4(d)). In many experiments, a color change of rocks after high-temperature treatment has been reported [40-42], which may be due to the dehydration and oxidation of the iron-magnesium minerals. The micro area EDS results (Figure 5) of this experiment also indicate the presence of Fe element.

3.2. XRD Analysis Results. According to XRD diffraction results (Table 2), it can be seen that the main constituent minerals of granite are quartz, biotite, plagioclase, and hornblende, among which quartz, biotite, and plagioclase make up the highest proportions. By comparing the XRD results of the unheated and $600^{\circ} \mathrm{C}$ high-temperature treatments, it can be found that the main minerals constituting the granite have not changed significantly (Table 2 and Figure 6). This is consistent with the high-temperature exposure of granite reported by Chen et al. [41] and Shang et al. [43].

\subsection{Rock Mechanical Properties}

3.3.1. Fracture Toughness Test Results. According to the test results of SCB, the maximum load was brought into the fracture toughness expression (1) and the fracture toughness value of granite could be calculated as listed in Table 3. In order to display the results more intuitively, a box plot is shown in Figure 7.

The fracture test results show that the fracture toughness of granite specimen decreases significantly after $600^{\circ} \mathrm{C}$, as shown in Table 3 and Figure 7. For example, the average fracture toughness of SCB specimens with a radius of $50 \mathrm{~mm}$ measured at room temperature was $1.71 \mathrm{MPa} \cdot \mathrm{m}^{0.5}$. The average value of fracture toughness after $600^{\circ} \mathrm{C}$ is only $0.59 \mathrm{MPa} \cdot \mathrm{m}^{0.5}$, a decrease of $65.6 \%$. This is consistent with many test results of granite. For example, Nasseri et al. [10] tested granite at $800^{\circ} \mathrm{C}$ and found that its fracture toughness was only $10 \%$ of the original granite. Talukdar et al. [11] reported that the fracture toughness values of the three types of crystalline rocks after $600^{\circ} \mathrm{C}$ were greatly reduced, exceeding $50 \%$. At the same time, the fracture toughness results 


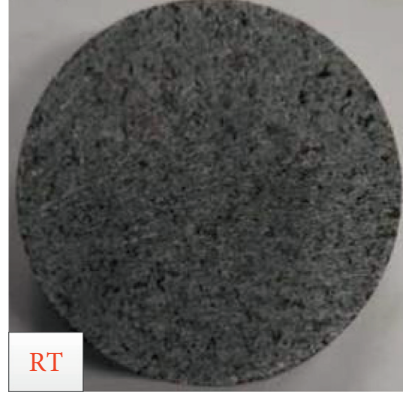

(a)

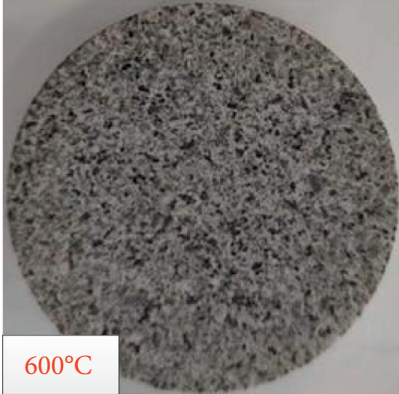

(b)

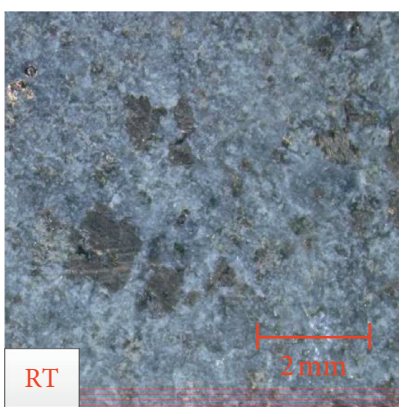

(c)

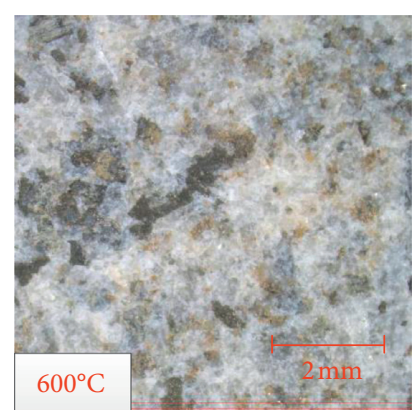

(d)

Figure 4: The surface color of granite (a, c) RT; (b, d) $600^{\circ} \mathrm{C}$; (c, d) USB Industrial Microscope (Shenzhen Jingtuo Youcheng Technology Co. Ltd, JT-H6)).

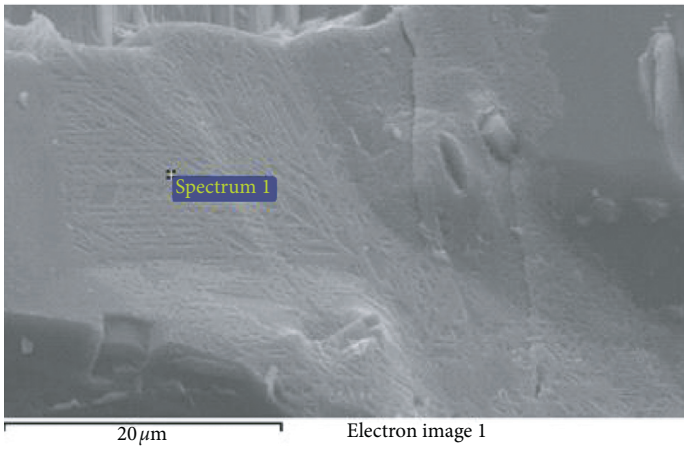

(a)

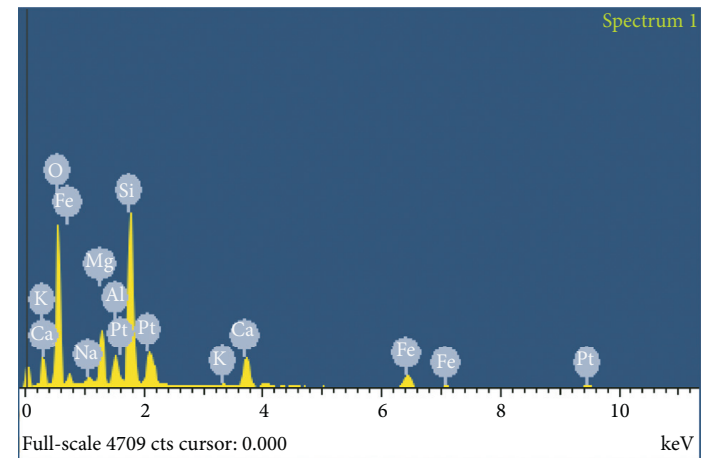

(b)

FIGURE 5: The result of energy-dispersive spectroscopy (EDS).

TABLE 2: XRD analysis results.

\begin{tabular}{lcccccccc}
\hline Mineral composition (\%) & Quartz & Biotite & Plagioclase & Hornblende & Orthoclase & Magnetite & Other & Total \\
\hline Granite at RT & 24.3 & 26.7 & 33.4 & 4.4 & 9 & 1.2 & 1 & 100 \\
Granite at $600^{\circ} \mathrm{C}$ & 22 & 24.4 & 30.5 & 4 & 7.8 & 1.3 & 10 & 100 \\
\hline
\end{tabular}

of SCB specimens with different radii after untreatment and high-temperature treatment were carefully compared (see Figure 7). It can be observed that as the diameter of the specimen increases, the fracture toughness value of untreated granite does not have a significant size effect. However, the fracture toughness value of granite after $600^{\circ} \mathrm{C}$ treatment increases obviously with the radii of specimens. Thus, the granite after high-temperature treatment shows a significant size effect, while the untreated granite shows no such phenomenon. Di Luzio et al. [25] also reported that concrete after heat loss also showed a significant size effect.

3.3.2. Tensile Strength Results. According to expression (2), the indirect tensile strength values of granite are calculated as shown in Table 4 . The results of tensile strength agree with the fracture test. The average tensile strength of the granite treated at $600^{\circ} \mathrm{C}$ was significantly reduced from $\sigma_{t}^{R T}=11.90 \mathrm{MPa}$ to $\sigma_{t}^{600^{\circ} \mathrm{C}}=4.19 \mathrm{MPa}$ at room temperature, a $64.8 \%$ decrease. This is very similar to the $65.6 \%$ reduction in the fracture test.

\subsection{Microstructure}

3.4.1. Results of Optical Microscope. After the fracture test was completed, the two types of granite $\left(\mathrm{RT}\right.$ and $\left.600^{\circ} \mathrm{C}\right)$ were placed in a vacuum chamber and impregnated with epoxy resin and then processed into slices which are 30 microns thick. In this way, the microcracks will be very easy to identify, as shown in Figure 8. After being impregnated with epoxy resin, the microcracks of the granite can be clearly observed. The mineral grains of the untreated granite (Figure 8(a)) are in close contact with only a few microcracks. The granite treated at $600^{\circ} \mathrm{C}$ is filled with a large amount of blue resin around the particles (Figure $8(\mathrm{~b})$ ), which means that many intercrystalline cracks have appeared. Obviously, the number and width of microcracks in the granite treated at $600^{\circ} \mathrm{C}$ are significantly increased compared with RT. To quantitatively analyze microcracks, Image J was used to identify microcracks filled with blue resin [44]. The software can accurately identify microcracks and highlight them in red, as shown in Figures 8(c) and 8(d). 


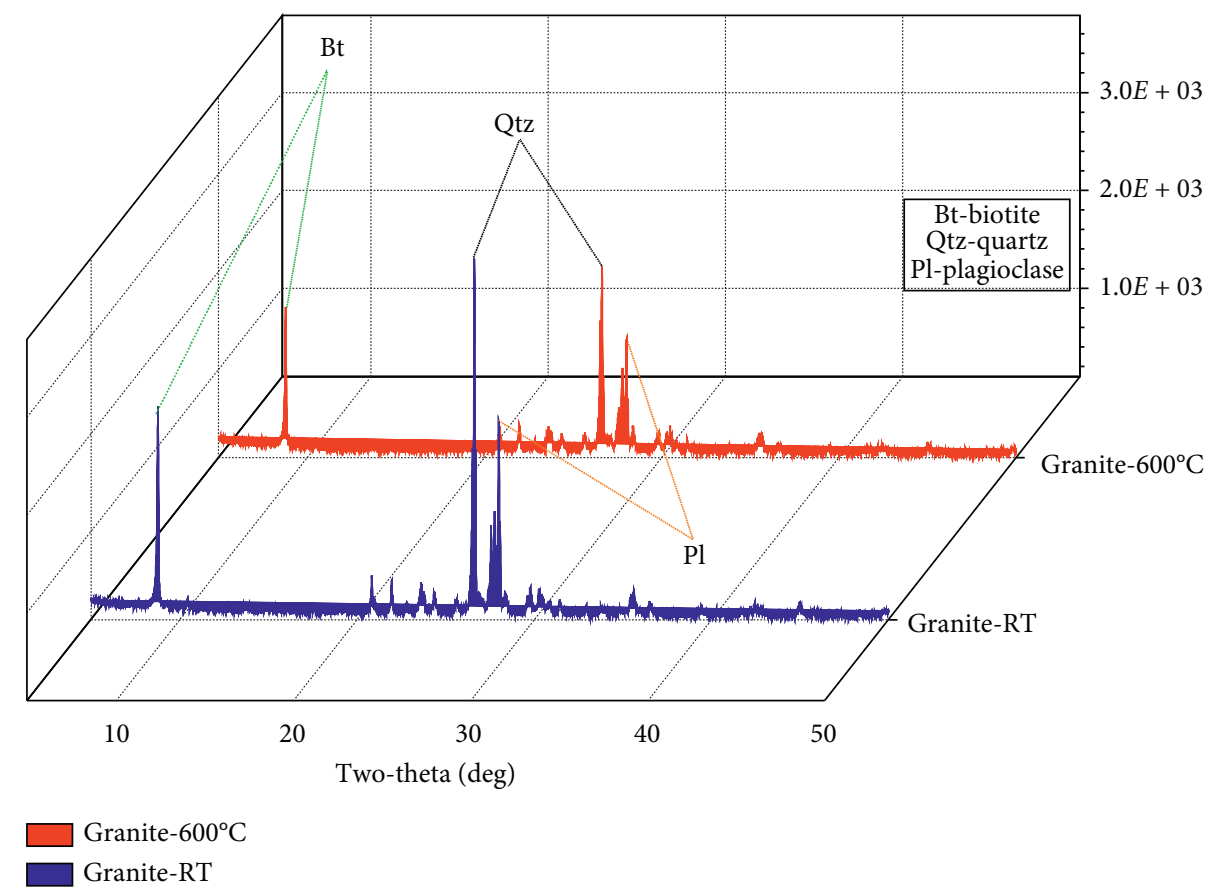

Figure 6: X-ray diffraction results of granite samples.

TABLE 3: The apparent fracture toughness.

\begin{tabular}{|c|c|c|c|c|c|c|c|}
\hline Heat treatment temperature & Specimen no. & $R(\mathrm{~mm})$ & $B(\mathrm{~mm})$ & $a_{0}(\mathrm{~mm})$ & $\begin{array}{c}\text { Effective structural } \\
\text { dimension, } D(\mathrm{~mm})\end{array}$ & Load, $P_{\max }(N)$ & $K_{\text {if }}\left(\mathrm{MPa} \cdot \mathrm{m}^{0.5}\right)$ \\
\hline \multirow{9}{*}{ RT } & S01 & 24.97 & 40.09 & 7.6 & 4.99 & 4472.4 & 1.65 \\
\hline & S02 & 24.96 & 40.15 & 7.56 & 4.99 & 5088.4 & 1.87 \\
\hline & S03 & 25.03 & 40.06 & 7.87 & 5.01 & 4389.9 & 1.62 \\
\hline & S04 & 48.29 & 40.13 & 15.03 & 9.66 & 5917.0 & 1.54 \\
\hline & S05 & 50.01 & 40.12 & 15.78 & 10.00 & 6291.6 & 1.64 \\
\hline & S06 & 49.96 & 40.02 & 15.07 & 9.99 & 6498.8 & 1.69 \\
\hline & S07 & 99.13 & 39.82 & 31.43 & 19.83 & 9992.3 & 1.84 \\
\hline & S08 & 99.15 & 40.04 & 30.73 & 19.83 & 9801.6 & 1.80 \\
\hline & S09 & 99.24 & 40.36 & 30.97 & 19.85 & 9658.3 & 1.78 \\
\hline \multirow{9}{*}{$600^{\circ} \mathrm{C}$} & S10 & 25.13 & 40.23 & 7.63 & 5.03 & 1156.9 & 0.43 \\
\hline & S11 & 25.14 & 40.33 & 7.67 & 5.03 & 1148.5 & 0.42 \\
\hline & S12 & 24.74 & 40.33 & 7.59 & 4.95 & 1708.7 & 0.63 \\
\hline & S13 & 49.36 & 40.21 & 15.43 & 9.87 & 1995.8 & 0.52 \\
\hline & S14 & 49.25 & 40.35 & 15.71 & 9.85 & 2090.1 & 0.54 \\
\hline & S15 & 50.07 & 40.23 & 15.92 & 10.01 & 2100.2 & 0.55 \\
\hline & S16 & 99.01 & 39.57 & 30.8 & 19.80 & 3210.6 & 0.59 \\
\hline & S17 & 99.55 & 40.52 & 30.44 & 19.91 & 3741.5 & 0.69 \\
\hline & S18 & 99.39 & 40.38 & 30.24 & 19.88 & 5086.9 & 0.94 \\
\hline
\end{tabular}

Note. The effective structural dimension $D$ is one of the parameters of the size effect law (SEL); see expression (7) for details (S01-S09, RT; S10-S18, 600 ${ }^{\circ} \mathrm{C}$ ).

In order to quantify the changes in the microstructure of granite, ImageJ software was used to identify and calculate the microcracks on the thin slices. The ImageJ analysis results show that the porosity (surface porosity) of the granite sample at RT is only $0.6 \%$, and this value becomes $4.7 \%$ after $600^{\circ} \mathrm{C}$, and the porosity increases significantly.

3.4.2. Results of SEM. There is a wealth of information on the fracture of the rock, and there are important traces of the fracture process of the rock, such as steps and river patterns. These important microscopic features can help us analyze the causes of rock failure during the fracture process [38]. SEM is an ideal tool for observing these characteristics, so we used SEM to observe and record the microscopic morphologies of the two types of granite fractures in detail, as shown in Figure 9. The particles of the original granite are flat and smooth, the steps and river patterns on the surface of the particles are not obvious, and there are no cracks between and within the particles, as shown in Figures 9(a) and 9(c). After treatment at 


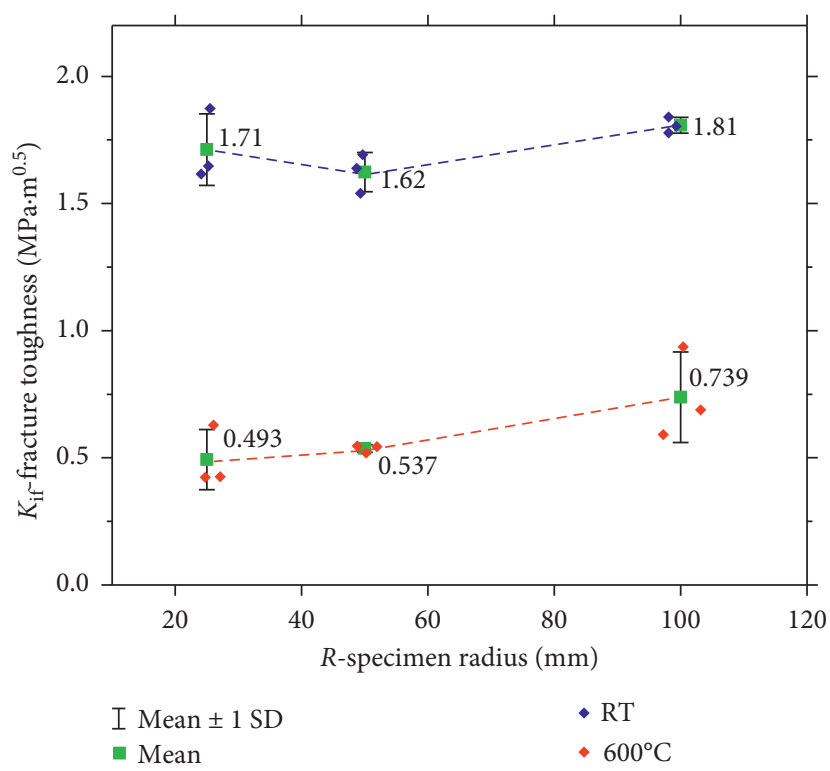

Figure 7: Box diagram of apparent fracture toughness for granite samples untreatment and after high-temperature treatment.

TABle 4: The Brazilian splitting test results.

\begin{tabular}{lcccccc}
\hline Specimen no. & $R(\mathrm{~mm})$ & $B(\mathrm{~mm})$ & Heat treatment temperature $\left({ }^{\circ} \mathrm{C}\right)$ & Peak strain $(\%)$ & Load, $P_{\max }(N)$ & $\sigma_{t}(\mathrm{MPa})$ \\
\hline B01 & 50.31 & 24.81 & $\mathrm{RT}$ & 0.80 & 22538.4 \\
B02 & 50.3 & 24.74 & $\mathrm{RT}$ & 0.71 & 25042.7 \\
B03 & 50.3 & 24.83 & $\mathrm{RT}$ & 0.85 & 11.50 \\
Average & & & 600 & 0.79 & 22606.7 \\
B04 & 50.54 & 24.94 & 600 & 0.79 & 11.50 \\
B05 & 50.58 & 24.8 & 600 & 0.79 & 10777.5 \\
B06 & 50.56 & 25.02 & & 0.78 & 8977.9 \\
Average & & & & 0.79 & 5086.9 \\
\hline
\end{tabular}

Note. B represents the Brazilian splitting test piece and RT indicates room temperature, without heat treatment.

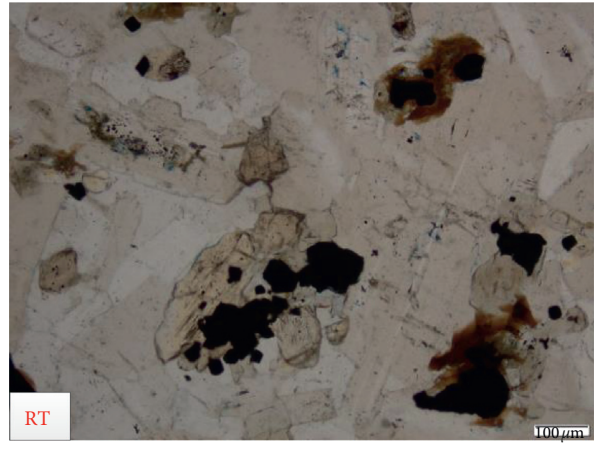

(a)

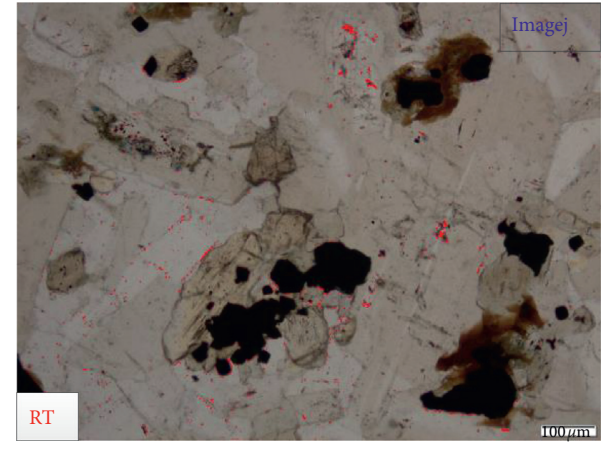

(b)

Figure 8: Continued. 


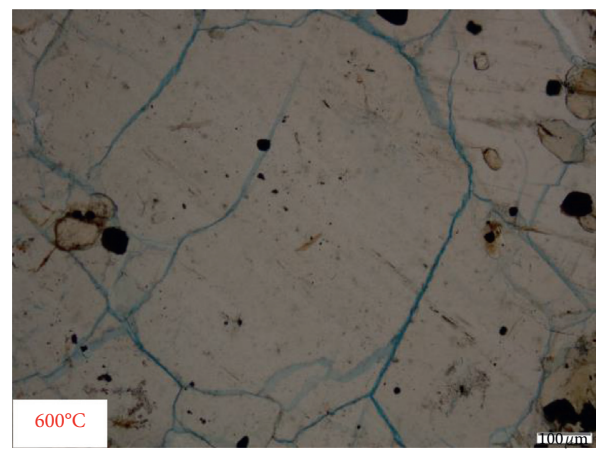

(c)

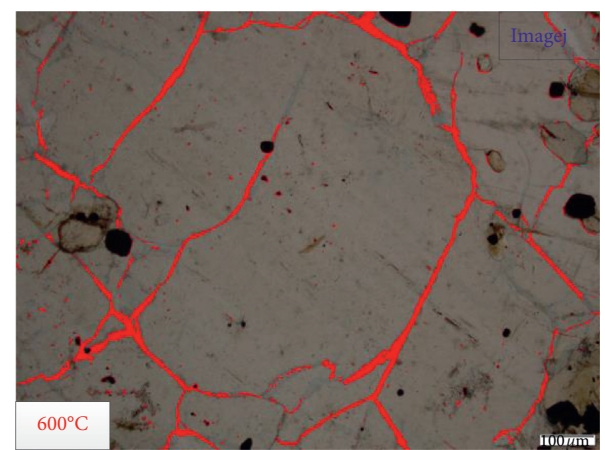

(d)

FIGURE 8: Photomicrographs of thin sections of granite samples (the red in (b) and (d) means that the ImageJ software identifies and counts the blue epoxy resin in diagrams (a) and (c)). (a and b) RT; (c and d) $600^{\circ} \mathrm{C}$.

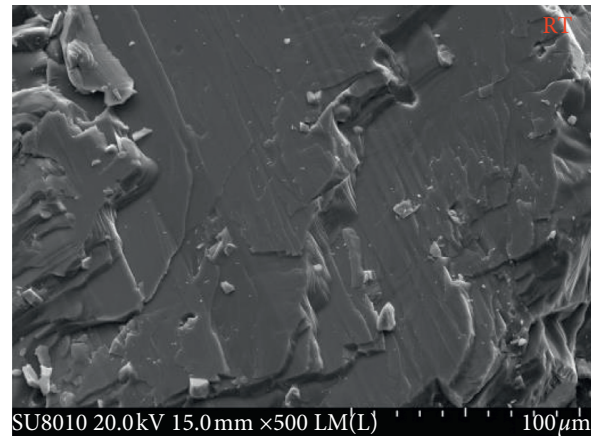

(a)

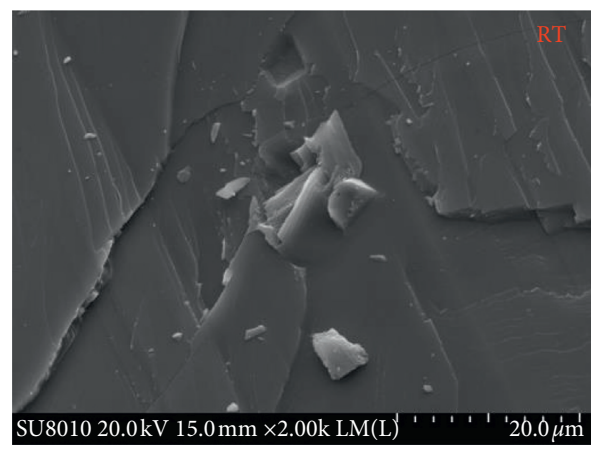

(c)

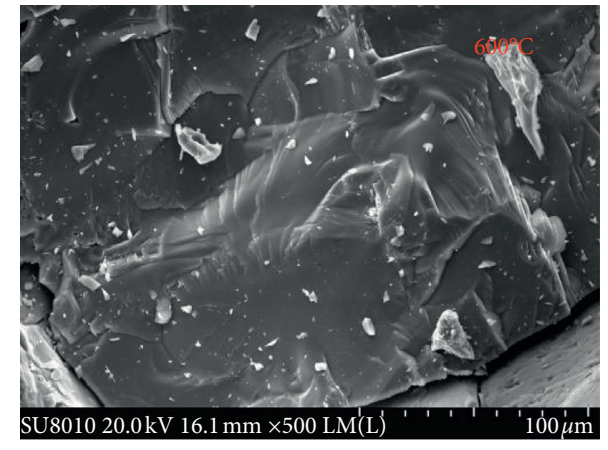

(b)

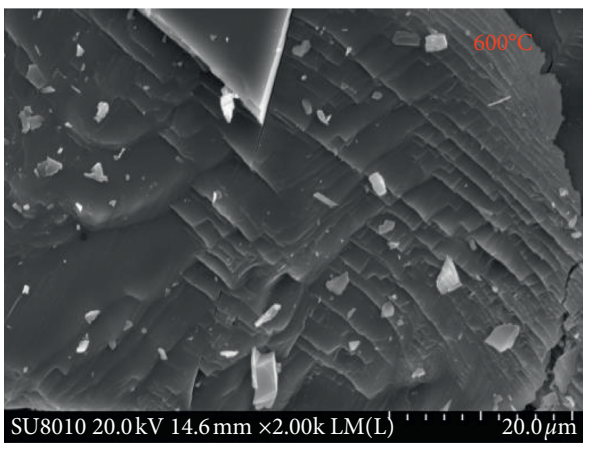

(d)

FIGURE 9: The untreated and heat-treated granite cleavage fracture microscopic morphology SEM images. (a, c) RT and (b, d) $600^{\circ} \mathrm{C}$.

$600^{\circ} \mathrm{C}$, the surface of granite mineral particles becomes rough, with obvious steps, river patterns, and cracks. This is similar to the experimental results of Talukdar et al. [11] on crystalline rocks. Zuo et al. [38] pointed out that temperature is an important factor affecting the fracture morphology of rocks. After high temperature, the rock failure mechanism changes from brittleness to brittleness and ductility.

\section{Discussion}

4.1. Size Effect Analysis. In order to solve the limitations of linear elastic mechanics, Bažant [24] proposed the famous size effect law (SEL) to study quasi-brittle materials. The specific formula is as follows:

$$
\begin{aligned}
& \sigma_{n}=c_{n} \sqrt{\frac{E G_{f}}{g\left(\alpha_{0}\right)^{\prime} c_{f}+d g\left(\alpha_{0}\right)}}, \\
& \sigma_{n}=c_{n} \frac{P}{t d} \\
& K=\frac{P}{b \sqrt{d}} \sqrt{g(\alpha)},
\end{aligned}
$$

where $\sigma_{n}$ is the nominal strength, $c_{n}$ is a coefficient, $t$ is the thickness, $d$ is the height, $P$ is the maximum load, $E$ is the elasticity modulus, $G_{f}$ is the fracture energy, $c_{f}$ is the 
effective fracture process zone length, and $\sqrt{g(\alpha)}$ is a form function associated with the specimen geometry. For some commonly used geometric forms, the specific expressions can be obtained by referring to the stress intensity factor manual. $K$ is fracture toughness, which can be derived from expressions (3)-(5):

$$
K_{i f}=\frac{K_{I C}}{\sqrt{1+\left(g^{\prime}\left(\alpha_{0}\right) c_{f} / g\left(\alpha_{0}\right) d\right)}}
$$

where $K_{i f}$ is the fracture toughness calculated by LEFM and $K_{I C}$ is the fracture toughness of an infinitely large specimen.

Expression (6) can be rewritten as

$$
\left\{\begin{array}{l}
\frac{1}{K_{i f}^{2}}=\frac{c_{f}}{K_{I C}^{2}} \frac{1}{D}+\frac{1}{K_{I C}^{2}}, \\
D=\frac{g\left(\alpha_{0}\right)}{g^{\prime}\left(\alpha_{0}\right)} d
\end{array}\right.
$$

where $D$ is the effective structural dimension. It is independent of the geometry of specimens.

The SCB experiment results (Table 3 ) are brought into expression (7) for linear fitting, and the results are shown in Figure 10. The linear fitting equations for untreatment and high-temperature treatment are as follows:

$$
\left\{\begin{array}{l}
\frac{1}{K_{i f}^{2}}=1.79765 E^{-16} \frac{1}{D}+3.23138 E^{-13}: R T, \\
\frac{1}{K_{i f}^{2}}=1.57411 E^{-14} \frac{1}{D}+1.50799 E^{-12}: 600^{\circ} \mathrm{C} .
\end{array}\right.
$$

According to the results of linear regression analysis, the size effect parameters $K_{\mathrm{IC}}$ and $c_{f}$ are obtained, which are listed in Table 5.

According to the results in Figure 10 and Table 5, it can be clearly seen that, for the untreated granite, $K_{I C}^{R T}=1.76$ $\mathrm{MPa} \cdot \mathrm{m}^{0.5}$ and $c_{f}^{R T}=0.56 \mathrm{~mm} . c_{f}^{R T}$ is very small, so the size effect of untreated granite is not significant, according to SEL. However, for the granite treated at $600^{\circ} \mathrm{C}, K_{I C}^{600^{\circ} \mathrm{C}}=0.81$ $\mathrm{MPa} \cdot \mathrm{m}^{0.5}$ and $c_{f}^{600^{\circ} \mathrm{C}}=10.4 \mathrm{~mm}$. Obviously, after $600^{\circ} \mathrm{C}$ treatment, the effective fracture process zone length $c_{f}$ of granite has increased significantly, so the size effect of thermal damaged granite is significant.

To more intuitively show the influence of $c_{f}$, the apparent fracture toughness values are normalized, as shown in Figure 11. $c_{f}$ is a key parameter to control the size effect as can be seen from the figure. The more significant the size effect is, the larger $c_{f}$ is. The results of this experiment also show that the size effect law of Bažant can well describe the size effect of granite after high-temperature treatment.

4.2. Effect of Temperature on $c_{f}$. According to the size effect law of Bažant, the size effect parameters of untreated and high-temperature treated granite samples are calculated. For untreated granite, $c_{f}^{R T}=0.56 \mathrm{~mm}$, while for granite treated

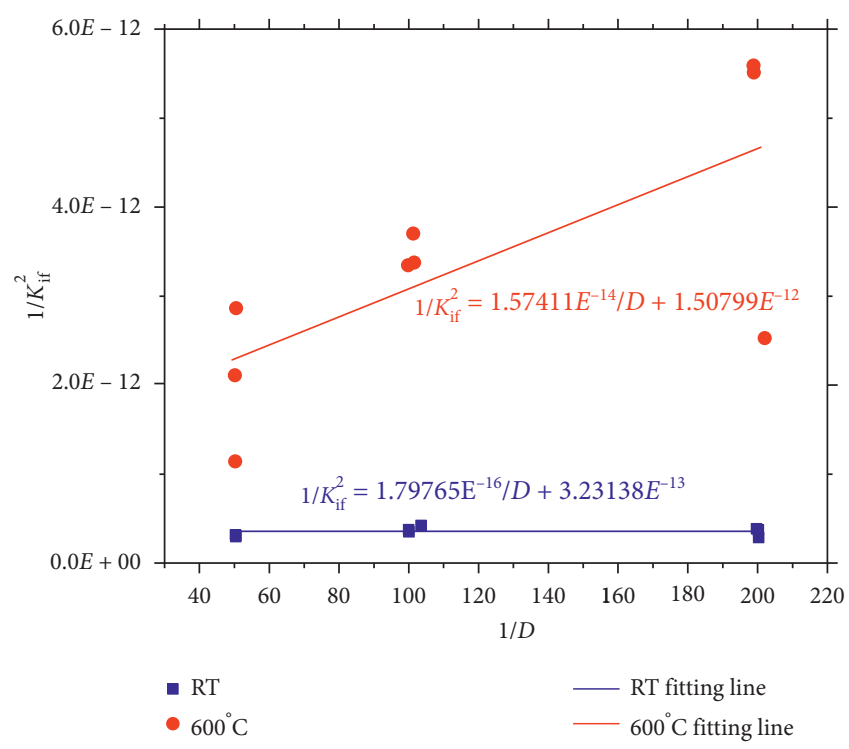

FIGURE 10: Linear regression for data from specimens of untreated granite samples and after $600^{\circ} \mathrm{C}$ treatment.

TABle 5: The size effect law (SEL) parameters of granite.

\begin{tabular}{lcc}
\hline Temperature & $K_{\mathrm{IC}}\left(\mathrm{MPa} \cdot \mathrm{m}^{0.5}\right)$ & $c_{f}(\mathrm{~mm})$ \\
\hline $\mathrm{RT}$ & 1.76 & 0.56 \\
$600^{\circ} \mathrm{C}$ & 0.81 & 10.4 \\
\hline
\end{tabular}

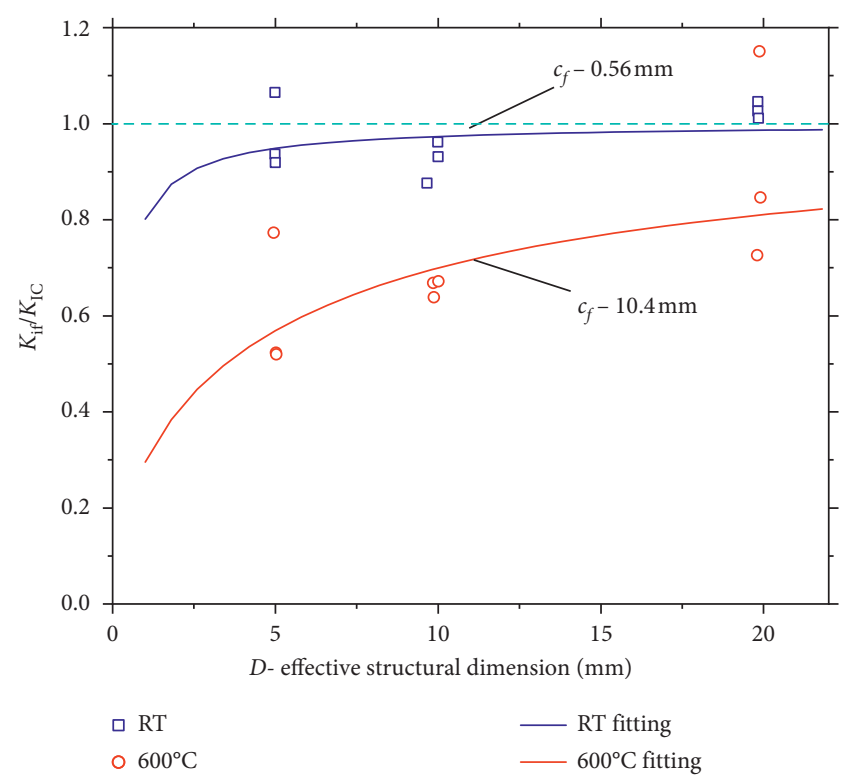

FIgURE 11: Variation of $K_{\mathrm{if}} / K_{\mathrm{IC}}$ of granite with the effective structural dimension (blue indicates room temperature, and red indicates after treatment at $600^{\circ} \mathrm{C}$ ).

at $600^{\circ} \mathrm{C}, c_{f}^{600^{\circ} \mathrm{C}}=10.4 \mathrm{~mm}$. The $c_{f}$ value increases significantly, which indicates that $600^{\circ} \mathrm{C}$ has a significant effect on the FPZ length of granite. The fracture process zone is closely related to the microcracks at the crack tip. High-temperature 
conditions will increase the microcracks of the rock, meaning that the FPZ of the rock increases after high temperature. These microcracks may be the main reason for the increase in FPZ.

After high temperature, there is more intuitive evidence for the increase of FPZ length of granite. Miao et al. [20] used DIC technology to observe the full-field displacement and strain of the granite surface and measured the FPZ length of the granite at different temperatures. The results show that the length of the FPZ increases along with processing temperature. Similarly, Yin et al. [21] used acoustic emission to monitor the three-point bending fracture process of granite treated at different temperatures. The results show that acoustic emission events occur only when the load is close to the peak for granite at room temperature $\left(25^{\circ} \mathrm{C}\right)$; this is a brittle fracture. However, the granite treated at high temperature (above $500^{\circ} \mathrm{C}$ ) exhibited a large number of acoustic emission events at lower loads (one-third of the maximum load), indicating that crack propagation occurred before reaching the maximum load.

These are consistent with the results of this test and prove that high-temperature conditions increase the length of the fracture process zone $\left(c_{f}\right)$ on rock. Both $c_{f}$ and $D$ have a significant effect on the size effect. The $K_{\mathrm{if}} / K_{\mathrm{IC}}$ values of the effective structure size $D \quad 0.005-0.2 \mathrm{~m}$ and $c_{f} 0.01-0.2 \mathrm{~m}$ are calculated according to expression (6). The $K_{\mathrm{if}} / K_{\mathrm{IC}}$ ratio decreases with $c_{f}$ and increases with $D$, as shown in Figure 12.

Therefore, for small samples and a large FPZ, the apparent fracture toughness value $K_{\text {if }}$ will be significantly underestimated. For example, for the heat-damaged granite samples in this test, the $K_{\text {if }}$ values of SCB specimens with $R=25 \mathrm{~mm}$ are significantly smaller than the $K_{\mathrm{IC}}$ value $\left(K_{i f}^{R=25}=0.493 \mathrm{MPa} \cdot \mathrm{m}^{\mathbf{0 . 5}} ; K_{I C}=0.81 \mathrm{MPa} \cdot \mathrm{m}^{\mathbf{0 . 5}}\right)$. In actual engineering, the core is often obtained through small boreholes to produce the specimens, and linear fracture mechanics are used to calculate the apparent fracture toughness parameters of the rock. However, the estimation of the fracture toughness of the actual structure often causes a large deviation. This will adversely affect the design and safety assessment of actual engineering structures, such as the exposure of rocks to high temperatures.

4.3. Estimate $K_{I C}$. The size effect law is inconvenient for the preparation of specimens of different sizes, which hinders the application of the size effect law. If only one size of specimens can be used, it is best that a single specimen can be used to estimate the size effect parameters, which will be very convenient and useful. Cedolin and Cusatis [45] established an equation for the relationship between tensile strength and size effect parameters, which can be used to easily estimate the size effect parameters. The equation is as follows:

$$
f_{t}=\sqrt{0.39 \frac{E G_{f}}{c_{f}}} .
$$

The above equation can be rewritten as

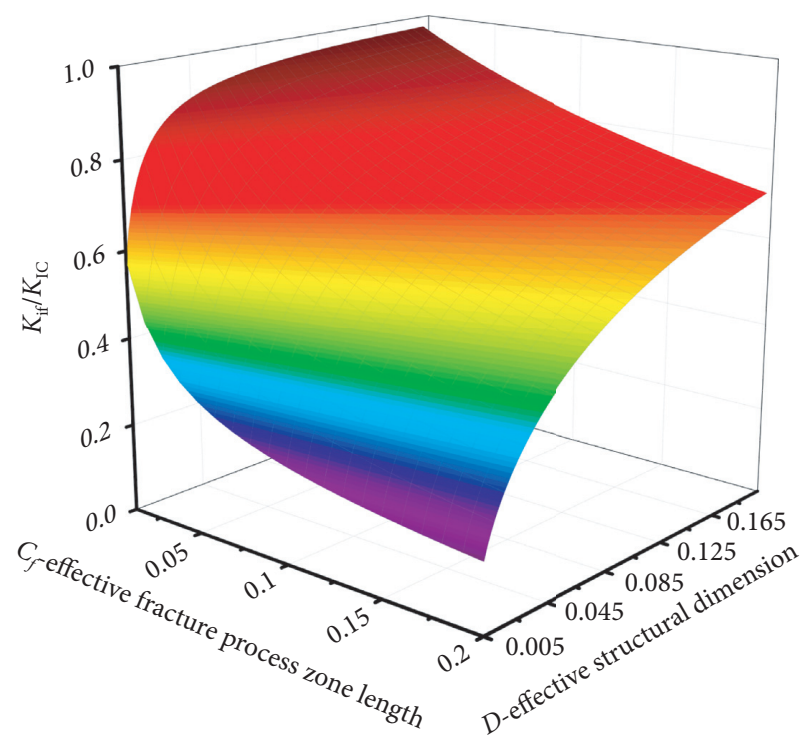

FIgURE 12: Three-dimensional surface plot as a function of $c_{f}$ and $D$.

$$
c_{f}=0.39\left(\frac{K_{I C}}{f_{t}}\right)^{2} .
$$

Combined with the size effect law (expression (6)), the following expression can be obtained:

$$
K_{I C}=\sqrt{\frac{1}{\left(1 / K_{i f}^{2}\right)-\left(0.39 / D f_{t}^{2}\right)}}
$$

To verify expression (11), the results of this experiment are brought into the expression as shown in Figure 13 and Table 6 . The results show that expression (11) can accurately predict the $K_{\mathrm{IC}}$ value of heat-damaged granite, but it shows a large deviation for untreated granite. As Cedolin and Cusatis [45] pointed out, expression (11) can only be applied when the ratio of the FPZ length to the size of the specimen reaches a certain range. Since the fracture process zone of untreated granite is very small, expression (11) is no longer applicable. For the heat-damaged rock, if its tensile strength is known, you can try to use expression (11) to estimate its $K_{\mathrm{IC}}$ value. If the tensile strength of the rock is unknown, the Brazilian splitting test can be used to estimate its tensile strength. Undoubtedly, more tests are needed to verify the above methods. It should also be noted that expression (11) estimates only one of the parameters of the size effect law, $K_{\mathrm{IC}}$, while the other parameter, $c_{f}$, is not recommended due to its large dispersion.

4.4. From Brittleness to Ductility. Bažant's brittleness number [46] is

$$
\begin{aligned}
\beta & =\frac{g\left(\alpha_{0}\right)}{g^{\prime}\left(\alpha_{0}\right)} \frac{d}{c_{f}} \\
& =\frac{D}{c_{f}},
\end{aligned}
$$




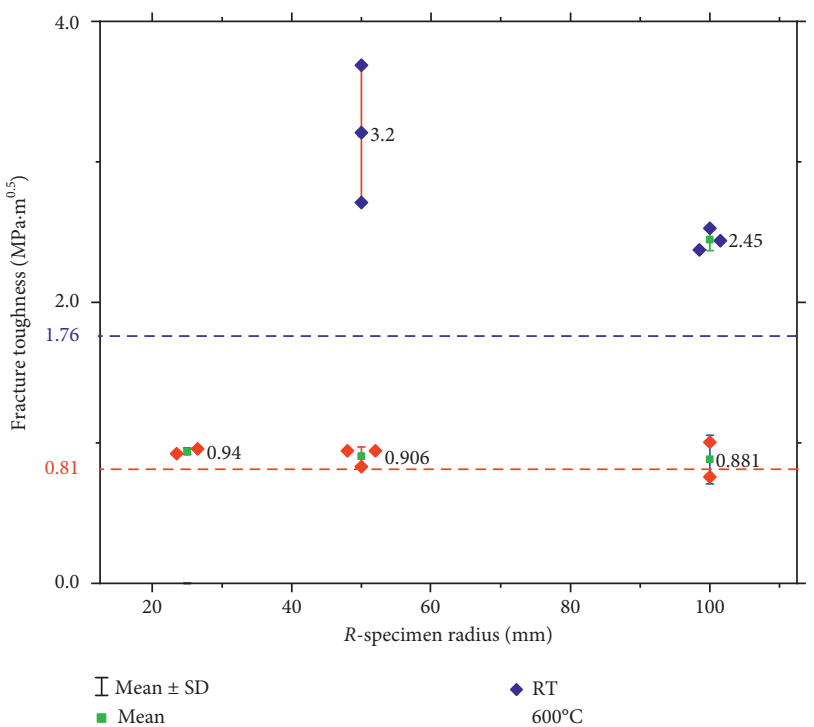

FIGURE 13: $K_{\text {IC }}$ estimated according to expression (11) (the dotted line represents the size effect parameter $K_{\text {IC }}$, while the blue- and reddotted lines represent the untreated granite and $600^{\circ} \mathrm{C}$ treated granite, respectively).

TABle 6: Comparison of $K_{\mathrm{IC}}$ estimated according to expression (11) and $K_{\mathrm{if}}$.

\begin{tabular}{lccc}
\hline & Effective structural dimension $D(\mathrm{~mm})$ & $K_{\text {if }}\left(\mathrm{MPa} \cdot \mathrm{m}^{0.5}\right)$ & $K_{\mathrm{IC}}$ estimated according to expression $(11)\left(\mathrm{MPa}-\mathrm{m}^{0.5}\right)$ \\
\hline S01 & 4.99 & 1.65 & -- \\
S02 & 4.99 & 1.87 & -- \\
S03 & 5.01 & 1.62 & 2.71 \\
S04 & 9.66 & 1.54 & 3.21 \\
S05 & 10.00 & 1.64 & 3.69 \\
S06 & 9.99 & 1.69 & 2.53 \\
S07 & 19.83 & 1.84 & 2.44 \\
S08 & 19.83 & 1.80 & 2.37 \\
S09 & 19.85 & 1.78 & 0.96 \\
S10 & 5.03 & 0.29 & 0.92 \\
S11 & 5.03 & 0.29 & -- \\
S12 & 4.95 & 0.43 & 0.83 \\
S13 & 9.87 & 0.36 & 0.94 \\
S14 & 9.85 & 0.37 & 0.94 \\
S15 & 10.01 & 0.37 & 0.76 \\
S16 & 19.80 & 0.41 & 1.00 \\
S17 & 19.91 & 0.46 & 6.67 \\
S18 & 19.88 & 0.63 & \\
\hline
\end{tabular}

where $D$ is the effective structural dimension.

Bažant's brittleness number of three sizes of specimens was calculated using (12), and the results are shown in Figure 14. Obviously, the brittleness of thermally damaged granite is significantly reduced. According to Bažant's standard [47], when $\beta>10$, the structure can be analyzed by elastic fracture mechanics; when $0.1<\beta<10$, the structure needs to be analyzed according to nonlinear fracture mechanics. Therefore, for $600^{\circ} \mathrm{C}$ treated granite samples, nonlinear fracture mechanics should be used for small specimens.

High temperatures usually reduce the brittleness of rock fractures and increase ductility. The $c_{f}$ value can also measure the degree of brittleness or ductility. Materials with larger process zones have more ductility [25]. The size effect parameter $c_{f}$ increases significantly after the granite samples are treated at $600^{\circ} \mathrm{C}$, indicating that the ductility of the granite increases. The experiments of Yin et al. [21] and Miao et al. [20] also showed that the ductility of thermally damaged granite increased.

At the same time, changes in microscopic features also confirm the increase in ductility. The scanning electron microscopy (SEM) results of fracture morphology shown in Figure 9 show that, in the thermally damaged granite samples, the cleavage becomes rough and the river pattern and step pattern are obvious, similar to the test results observed by Zuo et al. [39]. This change in fracture micromorphology indicates that the fracture behavior of granite changed from brittleness to ductility. 


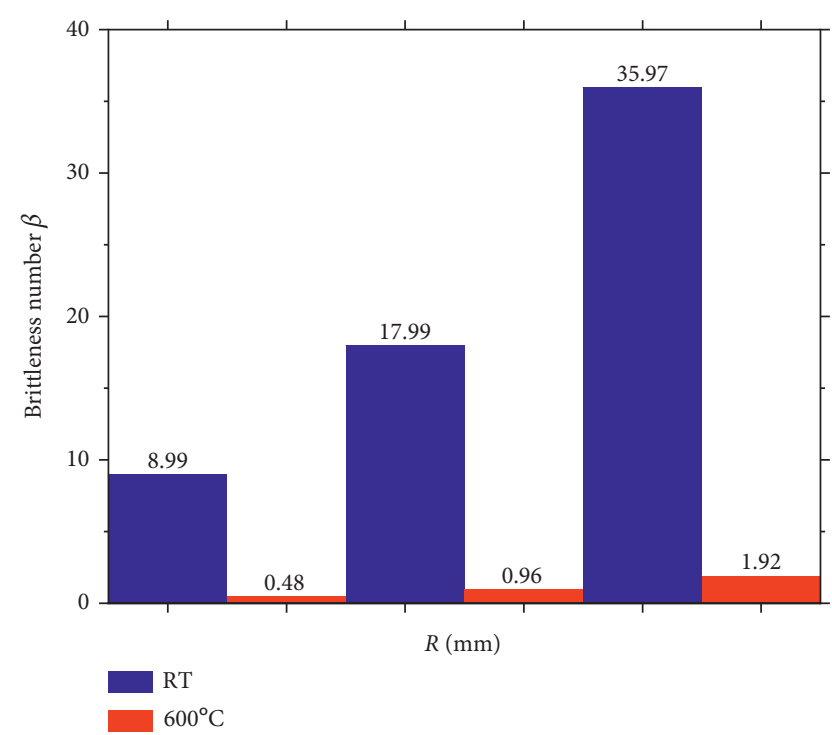

FIGURE 14: Bažant's brittleness number of three sizes of specimens (blue indicates untreated granite samples, and red indicates granite samples treated at $600^{\circ} \mathrm{C}$ ).

4.5. The Failure Mechanisms. The damage of granite due to high temperature is significant. The granite after the test is made into thin slices, and the optical microscope can be used to intuitively observe that the granite after high temperature has obvious microcracks. The number and width of microcracks are significantly increased compared to the original granite, as shown in Figure 8. This phenomenon can also be observed in the scanning electron microscope image (Figure 9).

During the heating process, the expansion coefficient and thermal conductivity of different grains of granite are different. For example, quartz has a higher thermal expansion coefficient than other minerals. At the same time, $600^{\circ} \mathrm{C}$ can cause the conversion of low quartz to high quartz $(\alpha-\beta)$ [46], which further aggravates the expansion of quartz particles. Therefore, during heating, due to inconsistent thermal strain, microcracks are likely to occur between the crystal grains. This is consistent with the observation in Figure 8. At the same time, in the cooling stage after the heating is completed, the crystal grains begin to shrink. This process is just the opposite of heating. Due to the different expansion coefficients, the deformation of different crystal grains during cooling is also different. Therefore, cooling also causes microcracks. This is the main failure mechanism of granite thermal damage.

The failure of the rock is closely related to the initiation and propagation of microcracks. There are a lot of microcracks in the thermally damaged rock. It is precisely because of their effects that an FPZ is formed at the crack tip. Therefore, the fracture process zone size of thermally damaged granite is significantly larger than that of original granite. The nonlinear characteristics of heat-damaged granite, such as size effect, become very obvious due to the influence of FPZ.

\section{Conclusions}

The obtained results of the research lead to the following conclusions:

(1) High temperature significantly weakens the fracture toughness value of granite.

The fracture toughness value of thermally damaged granite is significantly lower than that of untreated granite. For example, the average fracture toughness of SCB specimens $(R=50 \mathrm{~mm})$ measured at room temperature was $1.71 \mathrm{MPa} \cdot \mathrm{m}^{0.5}$, while the average fracture toughness after a temperature of $600^{\circ} \mathrm{C}$ was only $0.59 \mathrm{MPa} \cdot \mathrm{m}^{0.5}$, a decrease of $65.6 \%$.

(2) The granite has a significant size effect after treatment at $600^{\circ} \mathrm{C}$.

No obvious size effect was found in untreated granite; however, the size effect of granite after $600^{\circ} \mathrm{C}$ treatment increased significantly. The fracture toughness value of thermally damaged granite may be underestimated if linear elastic mechanics and small-sized specimens are applied directly.

(3) High-temperature conditions have a significant effect on the size effect parameters of granite.

The granite treated at $600^{\circ} \mathrm{C}$ had a nonnegligible fracture process area compared with untreated granite. For untreated granite, $c_{f}^{R T}=0.56 \mathrm{~mm}$, while for granite treated at $600^{\circ} \mathrm{C}, c_{f}^{600^{\circ} \mathrm{C}}=10.4 \mathrm{~mm}$. The value of $c_{f}$ increased significantly. The size effect law of Bažant was able to reasonably describe the fracture characteristics of thermally damaged granite.

(4) The microcracks of thermally damaged granite increase and the ductility increases.

After $600^{\circ} \mathrm{C}$, the microcracks of granite increased, the fracture morphology became rough, and ductility increased. The composition of thermally damaged granite did not change significantly, but the microcracks increased significantly, which may be directly related to the increase of $c_{f}$.

\section{Data Availability}

The data used to support the findings of this study are available from the corresponding author upon request.

\section{Conflicts of Interest}

The authors declare that there are no conflicts of interest.

\section{Authors' Contributions}

Zhongping Guo contributed to the conception of the study. Jian Li contributed significantly to design and wrote the manuscript. Yongqi Song performed the data analyses. 
Chengqian $\mathrm{He}$ and Fuyu Zhang helped perform the experiment.

\section{Acknowledgments}

The authors are very grateful to Professor Zhongming Yu of Liupanshui Normal University for his help. This work was supported by the Natural Science Research Project of Department of Education of Guizhou Province, China (Project no. Qianjiao He KY [2020]118), the Fund of Department of Education of Guizhou Province (Project nos. XKTJ[2020]23, [2016]02, and [2012]017), and the Fund of Department of Science and Technology of Guizhou Province (Project nos. [2014]7457 and [2019]5620).

\section{References}

[1] T. Yin, Y. Wu, C. Wang, D. Zhuang, and B. Wu, "Mixed-mode I + II tensile fracture analysis of thermally treated granite using straight-through notch Brazilian disc specimens," Engineering Fracture Mechanics, vol. 234, 2020.

[2] J.-P. Zuo, J.-T. Wang, Y.-J. Sun, and Y. Chen, G. H. Jiang and Y. H. Li, "Effects of thermal treatment on fracture characteristics of granite from Beishan, a possible high-level radioactive waste disposal site in China," Engineering Fracture Mechanics, vol. 182, pp. 425-437, 2017.

[3] H. Wagner, "Deep mining: a rock engineering challenge," Rock Mechanics and Rock Engineering, vol. 52, no. 5, pp. 1417-1446, 2019.

[4] A. Ghassemi, "A review of some rock mechanics issues in geothermal reservoir development," Geotechnical \& Geological Engineering, vol. 30, no. 3, pp. 647-664, 2012.

[5] J. Justo and J. Castro, "Mechanical properties of 4 rocks at different temperatures and fracture assessment using the strain energy density criterion," Geomechanics for Energy and the Environment, vol. 25, 2021.

[6] J. Li, Z.-W. Du, and Z.-P. Guo, "Effect of high temperature $\left(600^{\circ} \mathrm{C}\right)$ on mechanical properties, mineral composition, and microfracture characteristics of sandstone," Advances in Materials Science and Engineering, vol. 2020, Article ID 5072534, 19 pages, 2020.

[7] R. Tomas, J. I. Pagan, J. A. Navarro et al., "Semi-automatic identification and pre-screening of geological-geotechnical deformational processes using persistent scatterer interferometry datasets," Remote Sensing, vol. 11, no. 14, 2019.

[8] R. Tomas, A. Riquelme, M. Cano et al., "Evaluación de la estabilidad de taludes rocosos a partir de nubes de puntos 3D obtenidas con un vehículo aéreo no tripulado," Revista de Teledeteccion, vol. 55, pp. 1-15, 2020.

[9] M. Ghamgosar and N. Erarslan, "Experimental and numerical studies on development of fracture process zone (FPZ) in rocks under cyclic and static loadings," Rock Mechanics and Rock Engineering, vol. 49, no. 3, pp. 893-908, 2016.

[10] M. H. Nasseri, A. Schubnel, and R. P. Young, "Coupled evolutions of fracture toughness and elastic wave velocities at high crack density in thermally treated Westerly granite," International Journal of Rock Mechanics and Mining Sciences, vol. 44, no. 4, pp. 601-616, 2007.

[11] M. Talukdar, D. G. Roy, and T. N. Singh, "Correlating mode-I fracture toughness and mechanical properties of heat-treated crystalline rocks," Journal of Rock Mechanics and Geotechnical Engineering, vol. 10, no. 1, pp. 91-101, 2018.
[12] L. Chun, Y. Hu, T. Meng et al., "Mode-I fracture toughness and mechanisms of salt-rock gypsum interlayers under realtime high-temperature conditions," Engineering Fracture Mechanics, vol. 240, 2020.

[13] T. Yin, Q. Li, and X. Li, "Experimental investigation on mode I fracture characteristics of granite after cyclic heating and cooling treatments," Engineering Fracture Mechanics, vol. 222, Article ID 106740, 2019.

[14] V. Maruvanchery and E. Kim, "Effects of a high temperature $\left(500^{\circ} \mathrm{C}\right)$ on the fracture processes in calcite-cemented sandstone along bedding-plane orientations," Rock Mechanics and Rock Engineering, vol. 53, no. 2, pp. 955-966, 2020.

[15] B. Mahanta, T. N. Singh, and P. G. Ranjith, "Influence of thermal treatment on mode I fracture toughness of certain Indian rocks," Engineering Geology, vol. 210, pp. 103-114, 2016.

[16] Q. Li, T. Yin, X. Li, and S. Zhang, "Effects of rapid cooling treatment on heated sandstone: a comparison between water and liquid nitrogen cooling," Bulletin of Engineering Geology and the Environment, vol. 79, no. 1, pp. 313-327, 2020.

[17] Q. Guo, H. Su, J. Liu, Q. Yin, H. Jing, and L. Yu, “An experimental study on the fracture behaviors of marble specimens subjected to high temperature treatment," Engineering Fracture Mechanics, vol. 225, Article ID 106862, 2020.

[18] N. Erarslan, "Microstructural investigation of subcritical crack propagation and fracture process zone (FPZ) by the reduction of rock fracture toughness under cyclic loading," Engineering Geology, vol. 208, pp. 181-190, 2016.

[19] T. Funatsu, N. Shimizu, M. Kuruppu, and K. Matsuie, "Evaluation of mode I fracture toughness assisted by the numerical determination of K-resistance," Rock Mechanics and Rock Engineering, vol. 48, no. 1, pp. 143-157, 2015.

[20] S. Miao, P. Z. Pan, P. Yu, S. Zhao, and C. Shao, "Fracture analysis of Beishan granite after high-temperature treatment using digital image correlation," Engineering Fracture Mechanics, vol. 225, Article ID 106847, 2019.

[21] T. Yin, Y. Wu, Q. Li, C. Wang, and B. Wu, "Determination of double-K fracture toughness parameters of thermally treated granite using notched semi-circular bending specimen," Engineering Fracture Mechanics, vol. 226, Article ID 106865, 2020.

[22] J. Zuo, Y. Li, X. Zhang, Z. Zhao, and T. Wang, "The effects of thermal treatments on the subcritical crack growth of Pingdingshan sandstone at elevated high temperatures," Rock Mechanics and Rock Engineering, vol. 51, no. 11, pp. 34393454, 2018.

[23] S. Xu and W. Hans, "Reinhardt. determination of doubledetermination of double- $\mathrm{K}$ criterion for crack propagation in quasi-brittle fracture Part I: experimental investigation of crack propagation," International Journal of Fracture, vol. 98, no. 2, 1999.

[24] Z. P. Bažant, "Concrete fracture models: testing and practice," Engineering Fracture Mechanics, vol. 69, no. 2, pp. 165-205, 2002.

[25] G. Di Luzio, G. Muciaccia, and L. Biolzi, "Size effect in thermally damaged concrete," International Journal of Damage Mechanics, vol. 19, no. 5, pp. 631-656, 2010.

[26] J. Li, Z.-W. Du, Z.-P. Guo, and A. De-Chun, "Research on the size effect of unstable fracture toughness by the modified maximum tangential stress (MMTS) criterion," Advances in Civil Engineering, vol. 2020, Article ID 3986367, 10 pages, 2020.

[27] T. Tang, Z. P. Bažant, S. Yang, and D. Zollinger, "Variablenotch one-size test method for fracture energy and process 
zone length," Engineering Fracture Mechanics, vol. 55, no. 3, pp. 383-404, 1996.

[28] M. D. Kuruppu, Y. Obara, M. R. Ayatollahi, K. P. Chong, and T. Funatsu, "ISRM-suggested method for determining the mode I static fracture toughness using semi-circular bend specimen," Rock Mechanics and Rock Engineering, vol. 47, no. 1, pp. 267-274, 2014.

[29] I. Sedighi and R. Majid, "Ayatollahi,Bahador Bahrami. A statistical approach on the support type effect on mode I fracture toughness determined using semi-circular bend (SCB) specimen," Engineering Fracture Mechanics, vol. 226, 2020.

[30] ASTM D3967-16, Standard Test Method for Splitting Tensile Strength of Intact Rock Core Specimens, ASTM International, West Conshohocken, PA, USA, 2016.

[31] B. Rio and I. Nuroji, "Finite element modeling of concrete fracture in tension with the Brazilian splitting test on the case of plane-stress and plane-strain," Procedia Engineering, vol. 95, 2014.

[32] H. Su, Q. Guo, H. Jing, L. Yu, J. Liu, and Y. Gao, "Mechanical performances and pore features of coal subjected to heat treatment in approximately vacuum environment," International Journal of Geomechanics, vol. 20, no. 7, 2020.

[33] S. Shao, P. G. Ranjith, P. L. Wasantha, and B. K. Chen, "Experimental and numerical studies on the mechanical behaviour of Australian Strathbogie granite at high temperatures: an application to geothermal energy," Geothermics, vol. 2015, pp. 96-108, 2015.

[34] G. Feng, Y. Kang, T. Meng, Y. Q. Hu, and X. H. Li, “The influence of temperature on mode I fracture toughness and fracture characteristics of sandstone," Rock Mechanics and Rock Engineering, vol. 50, no. 8, pp. 2007-2019, 2017.

[35] S. Xu, M. A. Malik, Q. Li, and Y. Wu, "Determination of double-K fracture parameters using semi-circular bend test specimens," Engineering Fracture Mechanics, vol. 152, pp. 58-71, 2016.

[36] S. Dong, L. Zeng, C. Xu et al., "A novel method for extracting information on pores from cast thin-section images," Computers \& Geosciences, vol. 130, pp. 69-83, 2019.

[37] A. Hassan, V. Chandra, M. P. Yutkin, T. W. Patzek, and D. N. Espinoza, "Imaging and characterization of microporous carbonates using confocal and electron microscopy of epoxy pore casts," SPE Journal, vol. 24, 2019.

[38] S. Chen, Z. Du, Z. Zhang, H. Zhang, Z. Xia, and F. Feng, "Effects of chloride on the early mechanical properties and microstructure of gangue-cemented paste backfill," Construction and Building Materials, vol. 235, 2020.

[39] J. P. Zuo, H. P. Xie, H. W. Zhou, and S. P. Peng, “Thermalmechanical coupled effect on fracture mechanism and plastic characteristics of sandstone," Science in China-Series E: Technological Sciences, vol. 50, no. 6, pp. 833-843, 2007.

[40] Y. Qin, H. Tian, N. Xu, and Y. Chen, "Physical and mechanical properties of granite after high-temperature treatment," Rock Mechanics and Rock Engineering, vol. 53, no. 1, pp. 305-322, 2020.

[41] Y. Chen, S. Wang, J. Ni, R. Azzam, and T. M. FernandrazSteeger, "An experimental study of the mechanical properties of granite after high temperature exposure based on mineral characteristics," Engineering Geology, vol. 220, pp. 234-242, 2017.

[42] W. G. P. Kumari, P. G. Ranjith, M. S. A. Perera, B. K. Chen, and I. M. Abdulagatov, "Temperature-dependent mechanical behaviour of Australian strathbogie granite with different cooling treatments," Engineering Geology, vol. 229, pp. 31-44, 2017.

[43] X. Shang, Z. Zhang, X. Xu, Y. Liu, and H. Xing, "Mineral composition, pore structure, and mechanical characteristics of pyroxene granite exposed to heat treatments," Minerals, vol. 9, no. 9, 2019.

[44] J. Lai, G. Wang, Z. Fan et al., "Three-dimensional quantitative fracture analysis of tight gas sandstones using industrial computed tomography," Scientific Reports, vol. 7, no. 1, 2017.

[45] L. Cedolin and G. Cusatis, "Identification of concrete fracture parameters through size effect experiments," Cement and Concrete Composites, vol. 30, no. 9, pp. 788-797, 2008.

[46] B. Mahanta, P. G. Ranjith, V. Vishal, and T. N. Singh, "Temperature-induced deformational responses and microstructural alteration of sandstone," Journal of Petroleum Science and Engineering, vol. 192, Article ID 107239, 2020.

[47] Z. P. Bažant, Scaling of Structural Strength, Elsevier, Amsterdam, Netherlands, 2nd edition, 2005. 